\title{
Restoration of Elbow Flexion for Upper Trunk Brachial Plexus Injuries: Evaluation of Nerve Transfers and Modified Steindler Flexorplasty
}

\author{
Precious Grace B. Handog, MD,1* Tristram D. Montales, MD ${ }^{1 *}$ and Emmanuel P. Estrella, MD ${ }^{1,2}$ \\ ${ }^{1}$ Division of Hand and Reconstructive Microsurgery, Department of Orthopedics, Philippine General Hospital, University of the Philippines Manila \\ ${ }^{2}$ Institute of Clinical Epidemiology, National Institutes of Health, University of the Philippines Manila
}

\begin{abstract}
Introduction. In patients with delayed presentation between 6 to 12 months, surgical treatment guidelines are not well defined in brachial plexus injury. Still, several authors have agreed that functional outcomes in patients treated within six months from the date of injury have the best results. Nerve transfers are still considered one of the treatment options in the said subset of patients even after six months. In contrast, a primary Steindler flexorplasty, or proximal advancement of the flexor-pronator group, is an ideal technique for elbow flexion with an elapsed time from injury $>6$ to 9 months.
\end{abstract}

Objective. The purpose of this investigation was to compare the clinical outcome s of nerve transfers versus modified Steindler flexorplasty for the restoration of elbow flexion in upper type brachial plexus injuries (BPI).

Methods. A retrospective review of 28 patients who underwent nerve transfers (NT) and 12 patients who underwent modified Steindler flexorplasty (MSF) was done to determine the outcome of treatments. The manual muscle testing using the Medical Research Council scaling system, Visual Analog Scale for pain, active range of motion, and Disabilities of the Arm, Shoulder and Hand form scores were taken as dependent variables.

Results. The NT group had a median age of 27.5 years, with 26 men, a median surgical delay of 5.6 months, and a median follow-up of 33 months. Twenty out of 28 patients (71\%) had $\geq \mathrm{M} 3$ with a median range of $117.6^{\circ}$ elbow flexion motion. Median postoperative DASH $(n=16)$ and VAS scores were 29.2 and 3 , respectively. For the MSF patients, the median age was 27 years, including ten men, the median surgical delay was 12 months, and the median follow-up was 18.4 months. All the 12 patients had $\geq \mathrm{M} 3$, with a median range of motion of $106^{\circ}$. The median postoperative DASH score $(n=5)$ and VAS score were 28.3 and 0 , respectively. In the NT group, 73.3\% (11/15) achieved $\geq \mathrm{M} 3$ elbow flexion if the operation was done in $<6$ months.

Conclusion. Nerve transfers and the modified Steindler procedure are still excellent options for successful elbow flexion reanimation in patients with brachial plexus injuries. Our results also showed that those with surgical delays of less than six months had the highest rate of achieving $\geq \mathrm{M} 3$ elbow flexion strength in the nerve transfer group.

Key Words: brachial plexus injuries, nerve transfers, Steindler, elbow flexion

*Dr. Handog and Dr. Montales shared first authorship for this paper.

Corresponding author: Emmanuel P. Estrella, MD

Division of Hand and Reconstructive Microsurgery

Department of Orthopedics

Philippine General Hospital

University of the Philippines Manila

Taft Avenue, Ermita, Manila 1000, Philippines

Institute of Clinical Epidemiology

National Institutes of Health,

University of the Philippines Manila

Email: epestrella@up.edu.ph

\section{INTRODUCTION}

Brachial plexus injuries can sometimes result in significant upper extremity dysfunction and disability. Elbow flexion is often affected and considered the top priority in the restoration of upper extremity function. The biceps and brachialis muscles, both innervated by the musculocutaneous nerve from the $\mathrm{C} 5$ and $\mathrm{C} 6$ roots, mainly provide elbow flexion with supplemental action from the brachioradialis muscle. The absence of clinical and electrophysiological recovery of these muscles for three months usually warrants 
surgery for adequate restoration of function. ${ }^{1}$ Treatment options to restore elbow flexion are based on several factors, including the timing of surgery, available muscle for transfer, the extent of injury, and surgeon and patient. ${ }^{1,2}$ Injuries to the musculocutaneous nerve, the lateral cord, or upper trunk of the brachial plexus are often addressed with primary nerve reconstruction if done early enough; ideally, less than six months post-injury. Management includes direct nerve repair, nerve grafting, or nerve transfers. ${ }^{1-13}$

In traction injuries, large nerve gaps, proximal injuries, and avulsion-type injuries, the direct repair is often not possible. In these cases, nerve transfer procedures are often used for nerve reconstruction. In 2011 and 2012, Garg et al. and Yang et al. published two systematic reviews for nerve repair, nerve grafting, and nerve transfers. ${ }^{5,6} \mathrm{Garg}$ et al. concluded that elbow flexion using nerve transfers are better than nerve grafting, achieving $83 \%$ of their patient population gaining muscle strength of at least M4 for nerve transfers versus $56 \%$ for nerve grafting. Similarly, in the systematic review of Yang et al., 71\% of 352 patients had at least M4 for nerve transfers and $46 \%$ of 91 cases for nerve repair. ${ }^{6}$ Several intra- and extra-plexal nerves can be used as donors for nerve transfers. These include the spinal accessory nerve, intercostal nerve, phrenic nerve, ulnar nerve fascicle/s, median nerve fascicle/s, contralateral $\mathrm{C} 7$, thoracodorsal nerve, pectoral nerve, phrenic nerve, and hypoglossal nerve.,

In cases wherein patients are seen later than 12 months after the injury, secondary reconstruction such as tendon or muscle transfers, free functioning muscle transfers, and bony or soft tissue procedures may be indicated and can be done anytime. ${ }^{1}$ Thereafter, primary nerve reconstruction such as nerve repair, nerve grafting, and nerve transfers become increasingly less reliable and will predictably fail when delayed for more than 12 months., ${ }^{2,9}$ One of the most commonly used is the proximal advancement of the flexor-pronator origin (Steindler's flexorplasty). ${ }^{14,15}$

Data on the ideal timing of nerve transfers have not yet been established, but several authors have agreed that functional outcomes in patients treated within six months from the date of injury have the best results. ${ }^{1-3}$ In our institution, nerve transfers are still considered one of the treatment options in the said subset of patients even after six months. In contrast, a primary Steindler flexorplasty, or proximal advancement of the flexor-pronator group, is an ideal technique for elbow flexion with an elapsed time from injury $>6$ to 9 months. ${ }^{14,15}$ The purpose of this investigation is to compare the functional outcomes of nerve transfers to modified Steindler flexorplasty for elbow flexion in upper type and extended upper type brachial plexus injuries.

\section{METHODOLOGY}

A retrospective review of all patients from January 2004 to December 2015 who underwent nerve transfers and modified Steindler procedure for elbow flexion in patients with upper type brachial plexus injuries was done. The inclusion criteria were all adult patients who underwent nerve transfers or modified Steindler flexorplasty procedure to restore elbow flexion after traumatic brachial plexus injuries with a follow-up of at least 12 months. The exclusion criteria were patients with obstetric brachial plexus injury, patients with complete brachial plexus injuries, patients with bilateral brachial plexus injuries, or those with a combination of nerve and muscle transfers for elbow flexion.

The records were reviewed to identify patients with a minimum follow-up of one year who underwent nerve transfers and/or modified Steindler flexorplasty for C5$\mathrm{C} 6, \mathrm{C} 5-\mathrm{C} 7$, or $\mathrm{C} 5-\mathrm{C} 8$ brachial plexus injury. The surgical technique initially described by Oberlin et al. in 1994 and the double nerve transfer described by Goubier et al. has been well described. ${ }^{3,8}$ Patients were classified according to the type of procedure performed: nerve transfers (Figures 1 and 2) and modified Steindler flexorplasty (MSF) procedure (Figure 3).

For the nerve transfer group, donor and recipient nerves were identified, and comparative data were analyzed within the group. Indications for nerve transfers include available nerve donors, injury of less than 12 months, and avulsion injuries of the cervical roots. The indications for the MSF were chronic injuries, weak or no available nerve donors, and the choice of the patient for earlier return of elbow flexion, as per division protocol.

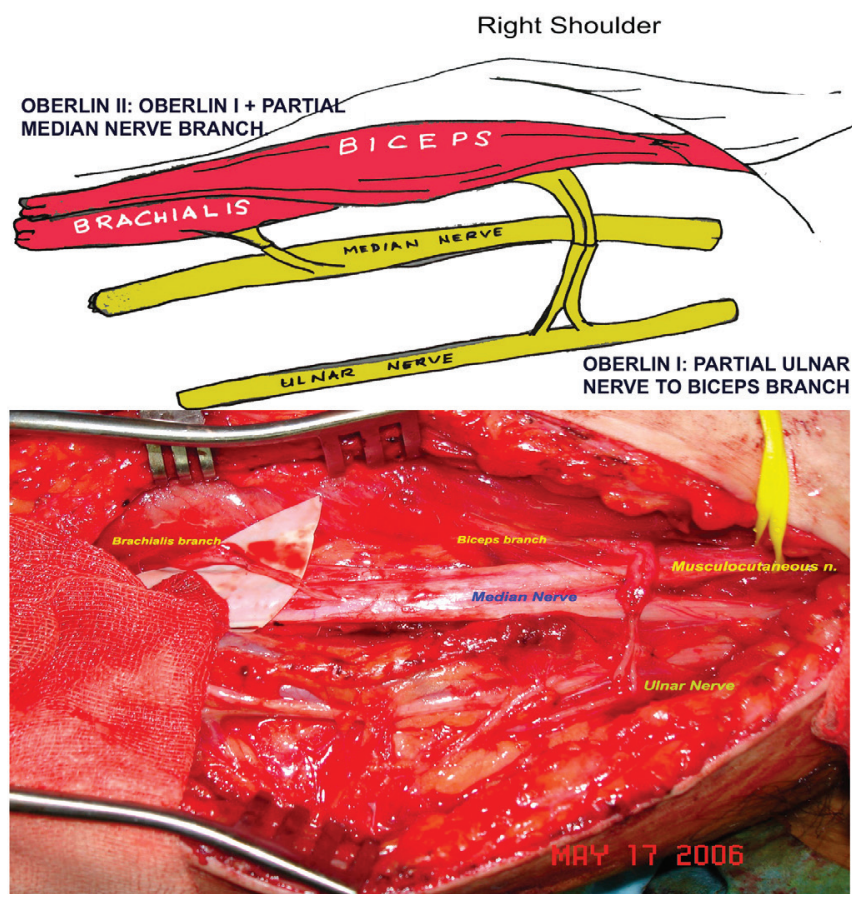

Figure 1. The Oberlin 2 procedure. Partial ulnar nerve and partial median nerve transfer to the biceps and brachialis branch of the musculocutaneous nerve. 

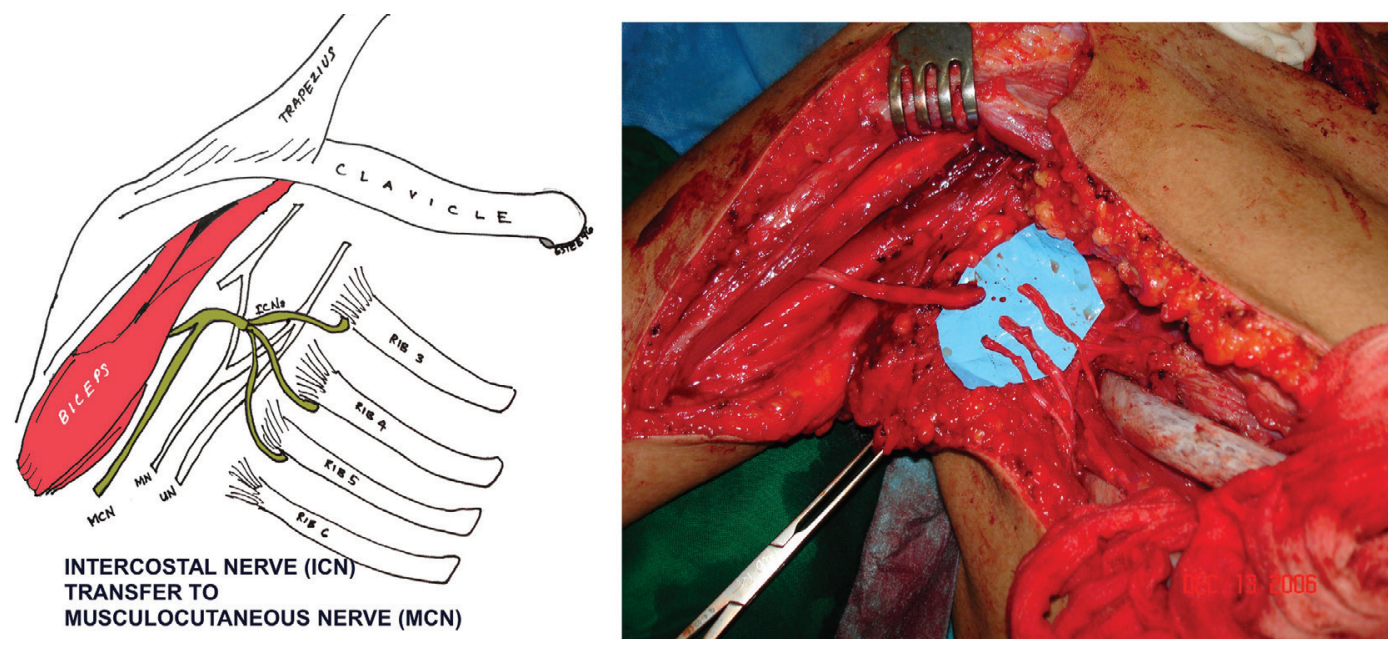

Figure 2. Intercostal nerve transfer ( $3^{\text {rd }}$ to $5^{\text {th }}$ intercostal nerve) to the musculocutaneous nerve.
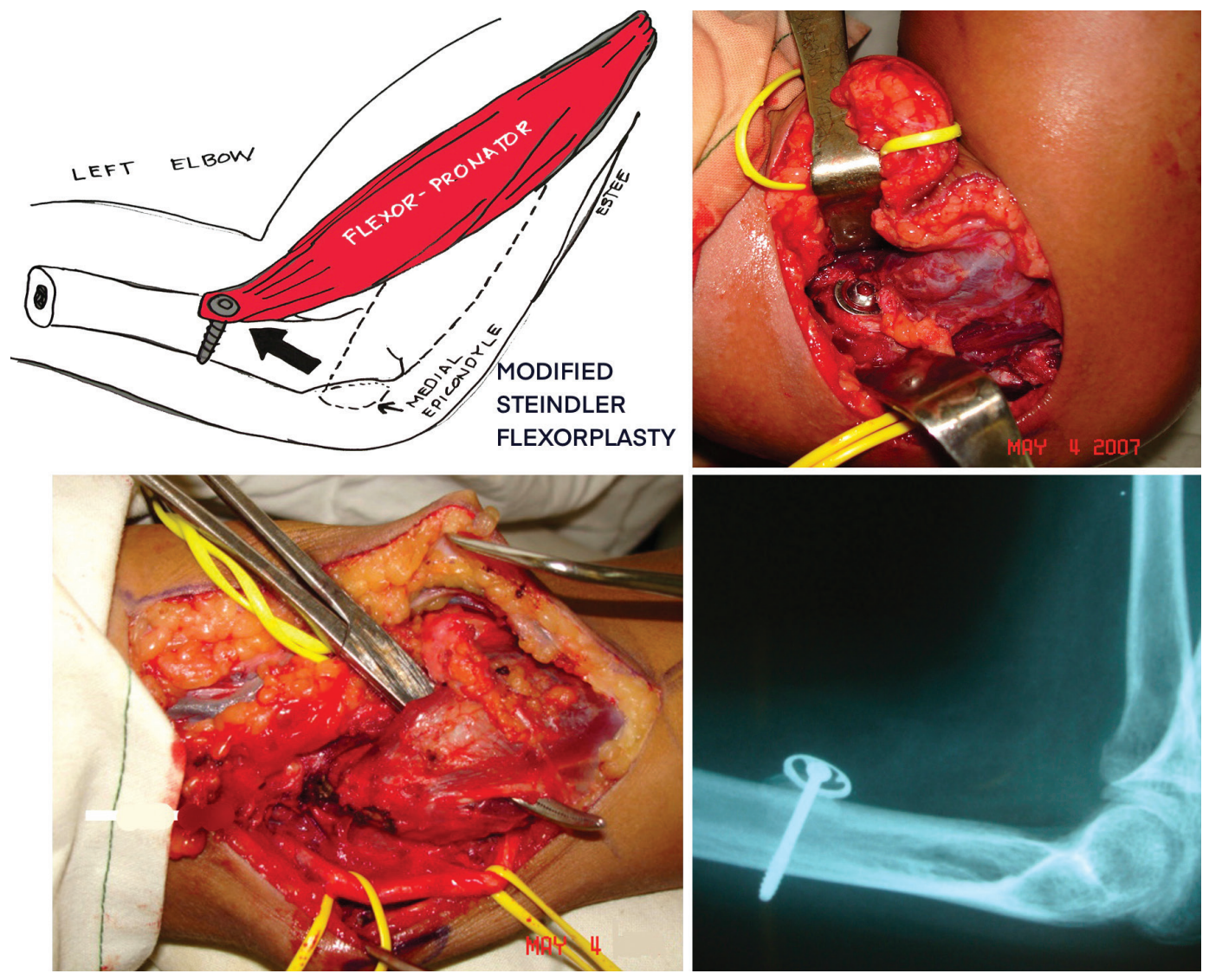

Figure 3. Modified Steindler flexorplasty. Flexor-pronator muscle origin transfer to the distal humerus.

\section{Clinical Outcomes}

The evaluation of the muscle strength was assessed according to the modified research council grading (preoperatively and postoperatively) in all patients. ${ }^{16}$

Active range of motion for elbow flexion was assessed using a standard goniometer (12-inch). The evaluation was measured in degrees (extension and flexion). The FIL-
DASH questionnaire was used to assess function. The higher the FIL-DASH score, the greater the disability. Pain was assessed using the visual analogue scale (0-no pain, 10 -worst pain imaginable). Complications and secondary or salvage procedures were noted and recorded.

All data were encoded in Microsoft Excel for Windows ${ }^{\mathrm{TM}}$. 
Table 1. Demographic summary of the Nerve transfer and the Modified Steindler flexorplasty group

\begin{tabular}{|c|c|c|}
\hline & $\begin{array}{c}\text { Nerve } \\
\text { Transfer } \\
(\mathbf{n}=28)\end{array}$ & $\begin{array}{c}\text { Modified } \\
\text { Steindler } \\
(n=12)\end{array}$ \\
\hline \multicolumn{3}{|l|}{ Gender } \\
\hline Male & 26 & 10 \\
\hline Female & 2 & 2 \\
\hline Age in years (median, IQR $R^{\#}$ ) & $27.5(22,47)$ & $27(24,40)$ \\
\hline Surgical delay in months (median, IQR) & $5.6(5,9)$ & $12(11,41)$ \\
\hline Follow-up in months (median, IQR) & $33(16,55)$ & $18.4(13,44)$ \\
\hline \multicolumn{3}{|l|}{ Roots involved } \\
\hline C5C6 (\%) & $11(39.3)$ & $5(41.7)$ \\
\hline C567/C8 (\%) & $17(60.7)$ & $7(58.3)$ \\
\hline \multicolumn{3}{|l|}{ Nerve Transfers Type } \\
\hline Oberlin I^ & $7(25)$ & NA \\
\hline Oberlin $I^{\wedge \wedge}$ & $16(57)$ & \\
\hline $\mathrm{ICN}^{-\mathrm{MCN} \&}$ & 4 & \\
\hline PMN-Biceps Branch* & 1 & \\
\hline
\end{tabular}

\#IQR - Interquartile distance; ${ }^{\wedge}$ Oberlin I - partial ulnar nerve fascicle to biceps nerve branch; ${ }^{\wedge}$ Oberlin II - Oberlin I + partial median nerve fascicle to brachialis nerve branch; ${ }^{\prime} \mathrm{CNN}-\mathrm{MCN}$ - Intercostal nerves to musculocutaneous nerve; ${ }^{*} \mathrm{MN}$-Biceps Branch - partial median nerve fascicle to brachialis nerve branch.

\section{RESULTS}

Fifty-three patients were reviewed, but only 28 of the nerve transfer patients and 12 of the modified Steindler patients fulfilled the inclusion criteria for the study. The nerve transfer procedures were done either using the dual transfers: Oberlin I procedure (partial ulnar nerve [PUN] to the motor branch of the musculocutaneous nerve to the biceps) or Oberlin II / Dual nerve transfers (Oberlin I + partial median nerve $[\mathrm{PMN}]$ to the motor branch of the brachialis) The other nerve transfers were intercostal nerve transfers to the musculocutaneous nerve and isolated PMN transfer to the brachialis branch. The Steindler technique modified by Brunelli was used for the Steindler flexorplasty. ${ }^{14}$

\section{Demographic Data: Nerve Transfer (NT) vs. Modified Steindler Flexorplasty (MSF) Group}

The median age of the NT group was at 27.5 years, with 26 males and two females. Nerve transfer surgery was performed at a median time of 5.6 months post-injury. There were 12 patients included in the MSF group. The median age was 27 years, with ten males and two females. Fifteen out of 28 patients had surgery within six months post-injury, 11 patients between 6 to 12 months, and two patients more than 12 months. A demographic summary of the patients in the two groups is shown in Table 1.

\section{Clinical Outcomes}

Twenty out of 28 NT patients, or $71 \%$, had at least an MRC grade of $\mathrm{M} 3$ with a mean active range of motion
Table 2. Summary of clinical outcomes for Nerve transfer and the Modified Steindler flexorplasty group

\begin{tabular}{|c|c|c|}
\hline & $\begin{array}{l}\text { Nerve Transfer } \\
\quad(n=28)\end{array}$ & $\begin{array}{c}\text { Modified } \\
\text { Steindler }(n=12)\end{array}$ \\
\hline $\begin{array}{l}\text { Muscle Strength } \geq M 3(\%) \\
\quad(\text { median, IQR })\end{array}$ & $\begin{array}{c}20(71.4 \%) \\
3.8(2,4) \\
\end{array}$ & $\begin{array}{c}12(100 \%) \\
4(3.9,4) \\
\end{array}$ \\
\hline $\begin{array}{l}\text { Range of motion in degrees } \\
\text { (median, IQR) }\end{array}$ & $\begin{array}{c}120^{\circ} \\
(110,130)\end{array}$ & $\begin{array}{c}105^{\circ} \\
(90,132.5)\end{array}$ \\
\hline $\begin{array}{l}\text { FIL-DASH Score } \\
\text { (median, IQR) }\end{array}$ & $\begin{array}{c}n=16 \\
29.2(23.9,45)\end{array}$ & $\begin{array}{c}\mathrm{n}=5 \\
28.3(26.7,32.9)\end{array}$ \\
\hline $\begin{array}{l}\text { VAS Score for Pain } \\
\text { (median, IQR) }\end{array}$ & $3(0,5)$ & $0(0,0.5)$ \\
\hline \multicolumn{3}{|l|}{ Nerve Transfers Type ( $\geq$ M3) } \\
\hline Oberlin $I^{\wedge}(n=7)$ & 5/7 (71.4\%) & NA \\
\hline Oberlin $I^{\wedge \wedge}(n=16)$ & $12 / 16(75 \%)$ & \\
\hline ICN-MCN\& $(n=4)$ & $3 / 4(75 \%)$ & \\
\hline PMN-Biceps Branch* $(n=1)$ & 0 & \\
\hline
\end{tabular}

"IQR - Interquartile distance; ^Oberlin I - partial ulnar nerve fascicle to biceps nerve branch; ${ }^{\wedge}$ Oberlin II - Oberlin I + partial median nerve fascicle to brachialis nerve branch; ${ }^{I} \mathrm{CN}-\mathrm{MCN}$ - Intercostal nerves to musculocutaneous nerve; *MN-Biceps Branch - partial median nerve fascicle to brachialis nerve branch.

of $117.6^{\circ}$ (median, $120^{\circ}$ ) elbow flexion. Fifteen out of 28 (53.5\%) had MRC of M4, while 5/28 had MRC M3. Among the four nerve transfer procedures, the Oberlin II and the ICN to the MCN had the highest success rate, both at $75 \%$. Still, the Oberlin II had a higher active elbow flexion of $128.9^{\circ}$ versus $113.8^{\circ}$ for the ICN to MCN. The Oberlin I was the second-highest success rate at $71 \%$, with active range of motion of $96.7^{\circ}$. The only case of $\mathrm{PMN}$ to $\mathrm{MCN}$ scored an MRC grade of $\mathrm{M} 2$ with an active range of motion without gravity at $100^{\circ}$. Median postoperative FIL-DASH scores and VAS scores were 32.9 (SD 16.4) and 3.0 (SD 3.0), respectively. The higher the FIL-DASH score, the greater the disability. A summary of the clinical results comparing NT and MSF is summarized in Table 2.

We also analyzed surgical delay and clinical muscle recovery for nerve transfers. Those operated less than six months had the highest recovery in terms of achieving $\geq \mathrm{M} 3$ elbow flexion strength (73.3\%; 11 out of 15$)$, followed by those with a delay of $6-12$ months $(63.6 \%, 7 / 11)$ and those $>12$ months $(50 \%, 1$ out of 2$)$. In the two cases where NT was done more than 12 months post-injury, one patient had M4 while the other had M2 on final follow-up.

Three NT patients with an MRC grade of M0 were advised for secondary reconstruction; however, one was lost to follow-up. One patient underwent Modified Steindler Flexorplasty, and the other one, a latissimus dorsi-pectoralis major muscle transfer. The patient who underwent the MSF had MRC grade M3, with 30 to $100^{\circ}$ active ROM at 48 months after her second surgery. 
One complication was noted in the MSF group. There was a screw cut out from the humeral cortex due to poor screw purchase two months after the surgery. Reattachment of the flexor-pronator mass to the humerus was revised using the pull-out technique. At 16 months follow-up, MRC was recorded to be at M4 with an active ROM of $0-75^{\circ}$.

\section{DISCUSSION}

Nerve transfers and Steindler flexorplasties have been two of the most common methods of restoring elbow flexion in patients with upper type brachial plexus injuries. ${ }^{1}$

Oberlin initially described the transfer of the ulnar nerve fascicle to the biceps motor branch. ${ }^{3}$ Since then, several authors have reported good outcomes in the restoration of elbow flexion. Recent systematic reviews on nerve transfers showed that the Oberlin procedure had better outcomes than nerve grafting and other neurotization techniques. ., $, 10-13,17^{-17}$

Steindler procedures, on the other hand, also had good outcomes, especially in cases where failed nerve surgery or in chronic cases where nerve surgery cannot be done. . $^{14,15}$

Brunelli and Brunelli using the modified Steindler procedure published results of a 20 -year retrospective study. ${ }^{14}$ The modification from the classic Steindler flexorplasty involved transferring of the flexor carpi ulnaris, flexor carpi radialis, and pronator teres together with a portion of the medial epicondyle to the anterior aspect of the humerus. The flexor digitorum superficialis was not included in the transfer. The concept of this modification improved hand function because it avoids both finger flexion and pronation during elbow flexion, known as the "Steindler effect." Thirty-two cases were included in their review. Twenty-six patients had at least elbow flexion of $100^{\circ}$ and were able to lift at least $2 \mathrm{~kg}$ weight. They concluded that this type of modification avoided the Steindler effect in $88 \%$ of cases. ${ }^{14}$

In 2011, Rezende et al. analyzed 11 patients with traumatic lesions of the upper trunk of the brachial plexus treated with Steindler procedure with at least six months follow-up. ${ }^{15}$ All subjects had elbow flexion strength between M2 and M3 preoperatively. Functionally, DASH scores improved postoperatively but were not statistically significant. They concluded that the modified Steindler procedure provided an effective gain of elbow strength and flexion in patients with high lesions of the brachial plexus, especially those presenting with an initial degree of elbow flexion strength of at least M2. ${ }^{15}$

This study showed a higher percentage achieving $\geq \mathrm{M} 3$ elbow flexion (12/12) after MSF compared to that of Chuang et al. (9/12). ${ }^{2}$ A similar result was also reported by Rezende et al., with 9 out of 11 (82\%) having a muscle grade of $\geq \mathrm{M} 3$, with an average elbow flexion of $94^{\circ} .{ }^{15}$

In this study, the clinical outcomes were comparable in terms of percent achieving $\geq \mathrm{M} 3$ elbow flexion strength, FILDASH score, elbow range of motion, and pain. The higher percentage of achieving $\geq \mathrm{M} 3$ for the MSF (100\%) versus
$74 \%$ for the NT might be explained by the shorter recovery of the tendon transfer. Normal or near-normal flexorpronator muscles were transferred. Nerve recovery usually takes a longer time to achieve $\geq \mathrm{M} 3$ elbow flexion. However, the FIL-DASH scores were similar on postoperative follow-up. The range of motion and pain were similar for both procedures.

One of the advantages of using the Steindler procedure is that rehabilitation is short since the transferred muscle is working. It can be used even in chronic cases. It can be a salvage procedure in failed nerve reconstructions. However, limitations include the Steindler effect ${ }^{14}$ where the forearm will go in pronation when activated. This is due to the pull of the flexor-pronator mass during activation, which causes pronation of the forearm, especially if placed ulnarly from the midline of the humerus. One way to counter-act this is to place the medial epicondyle more centrally or radially. This will not allow supination but can minimize pronation during activation. ${ }^{14}$ Another complication of MSF is the flexion contracture of around $10-30^{\circ}$. Because the origin is transplanted proximally of at least $5 \mathrm{~cm}$, flexion contracture is usually expected. The MSF is ideal for patients with chronic injuries and failed nerve surgeries with good muscle strength of the flexor-pronator muscles of at least M4/5. This procedure is also advised for patients who cannot wait for the one-year waiting recovery for nerve reconstruction, especially when the delay to surgery is bordering to 12 months.

Nerve transfers offer the advantage of physiologic restoration of elbow flexion, supination, shorter time to recovery than nerve grafts, and bypasses scarred tissues at the neck area. Nerve transfers allow a more physiologic restoration of elbow flexion compared to MSF. In nerve transfers, the biceps and/or brachialis muscle motion is restored, which are the physiologic flexors of the elbow. At the same time, the restoration of supination is achieved. The recovery of elbow flexion is much shorter in MSF compared to nerve transfer. This might explain the shorter follow-up in MSF, where $\geq \mathrm{M} 3$ is achieved earlier compared to NT. Given the advantages and disadvantages of both procedures, careful patient selection is needed to maximize the outcomes. In this case series, the restoration of elbow flexion achieving $\geq \mathrm{M} 3$ for both procedures was higher in the MSF (12/12) than NT (20/28).

Limitations of this study include a small sample size and the non-randomized allocation of treatment. This may contribute to the heterogeneity of the two groups. Longerterm follow-up for the MSF is also needed to determine possible long-term complications. Lastly, the FIL-DASH score was not taken for all patients and may not represent the actual FIL-DASH scores of each group.

\section{CONCLUSION}

In summary, nerve transfers and modified Steindler flexorplasty provided restoration of elbow flexion in patients 
with upper type or extended upper type brachial plexus injuries. Most of the patients achieved $\geq \mathrm{M} 3$ elbow flexion strength. Those operated before six months had a higher rate of achieving $\geq \mathrm{M} 3$ muscle strength than those operated after six months in nerve transfers. In contrast, the modified Steindler procedure was not correlated to the surgical delay.

\section{Statement of Authorship}

All authors participated in the data collection and analysis; agreement to be accountable for all aspects of the work and approved the final version submitted.

\section{Author Disclosure}

All authors declared no conflicts of interest.

\section{Funding Source}

No funding support.

\section{REFERENCES}

1. Gutowski KA, Orenstein HH. Restoration of Elbow Flexion after Brachial Plexus Injury: The Role of Nerve and Muscle Transfers. Plast. Reconstr. Surg. 2000; 106: 1348-57.

2. Chuang DC, Epstein MD, Yeh MC, Wei FC. Functional Restoration of Elbow Flexion In Brachial Plexus Injuries: Results In 167 Patients (excluding obstetric brachial plexus injury) 1993. J Hand Surg;18A:285-91.

3. Oberlin C, Beal D, Leechavengvongs S, Salon A, Dauge MC, Sarcy JJ. Nerve transfer to biceps muscle using a part of ulnar nerve for C5-C6 avulsion of the brachial plexus: anatomical study and report of four cases. J Hand Surg 1994;19A: 232e7.

4. Teboul F, Kakkar R, Ameur N, Beaulieu JY, Oberlin C. Transfer of Fascicles from The Ulnar Nerve to The Nerve to The Biceps in The Treatment of Upper Brachial Plexus Palsy. J Bone Joint Surg Am. 2004;86A:1485-90.

5. Garg R, Merrell GA, Hillstrom HJ, Wolfe SW. Comparison of Nerve Transfers and Nerve Grafting for Traumatic Upper Plexus Palsy: A Systemic Review and Analysis. J Bone Joint Surg Am. 2011; 93: 819-29.
6. Yang LJ, Chang KW, Chung KC. A Systematic Review of Nerve Transfer and Nerve Repair for the Treatment of Adult Upper Brachial Plexus Injury. Neurosurgery 2012; 71: 417-29.

7. Weber RW, Mackinnon SE. Nerve Transfers in the Upper Extremity 2004: J American Society for Surgery of the Hand: 4(3) 200-13.

8. Goubier JN, Teboul F. Technique of the Double Nerve Transfer to Recover Elbow Flexion in C5, C6 of C5 to C7 Brachial Plexus Palsy 2007: Techniques in Hand and Upper Extremity Surgery 11(1):15-17.

9. Lee SK, Wolfe SW. Nerve Transfers for the Upper Extremity: New Horizons in Nerve Reconstruction. J Am Acad Orthop Surg 2012;20:506-517.

10. Estrella EP. Functional outcome of nerve transfers for upper-type brachial plexus injuries. J Plastic, Reconstructive \& Aesthetic Surgery 2011;64:1007-1

11. Ali ZS, Heuer GG, Faught RW, Kaneriya SH, Sheikh UA, Syed IS, Stein SC, Zager EL. Upper brachial plexus injury in adults: comparative effectiveness of different repair techniques. J Neurosurg. 2015 Jan;122(1):195-201

12. Leechavengvongs $\mathrm{S}$, Witoonchart $\mathrm{K}$, Uerpairojkit $\mathrm{C}$, Thuvasethakul P, Ketmalasiri. Nerve Transfer to biceps Muscle Using a Part of the Ulnar Nerve in Brachial Plexus Injury (Upper Arm Type): A Report of 32 Cases. J Hand Surg 1998; 23A:711-16.

13. Leechavengvongs S, Witoonchart K, Uerpairojkit C, Thuvasethakul P, Malungpaishrope K. Combined Nerve Transfers for C5 and C6 Brachial Plexus Avulsion Injury 2006. J Hand Surg;31A:183-9.

14. Brunelli GA, Brunelli AV. Modified Steindler Procedure for Elbow Flexion Restoration. J Hand Surg 1995; 20A:743-6.

15. Rezende MR, Massa BS, Furlan FC, Mattar Junior R, de Paula EJ, Kimura LK et al. Evaluation of functional gain of the elbow following Steindler surgery for brachial plexus injury. Acta Ortop Bras 2011;19(3):154-8.

16. Medical Research Council. Aids to the Investigation of Peripheral Nerve Injuries. In War Memorandum No. 7, 2nd Ed. London: His Majesty's Stationery Office, 1943.

17. Ayhan E, Soldado F, Fontecha CG, Bertelli JA, Leblebicioglu G. Elbow flexion reconstruction with nerve transfer or grafting in patients with brachial plexus injuries: A systematic review and comparison study. Microsurgery. 2019. Feb 13. doi: 10.1002/micr.30440. [Epub ahead of print] Review. PMID:30761593 